\title{
LA RAZÓN Y LA FE EN LA CREACIÓN TEMPORAL DEL MUNDO
}

\author{
Ignacio M.? Azcoaga Bengoechea \\ Escuela Tomista de Barcelona. Miembro de la S.I.T.A.
}

Una de las cuestiones que más se ha debatido entre las escuelas filosóficas surgidas en el ámbito del cristianismo es: si la duración temporal finita del mundo es una verdad que queda al alcance de la razón humana, puesto que está vinculada al hecho de la creación y a la imposibilidad física del infinito, o si, teniendo en cuenta que el mundo pone de manifiesto su contingencia, su no necesidad, lo que supone tener su ser recibido del Ser Necesario, es posible que el mundo haya existido desde siempre. En otros términos, la cuestión discutida implica dos problemas muy disputados históricamente: la temporalidad del mundo deducida de su contingencia, basada en que una duración ilimitada implica recorrer el infinito y necesidad que es imposible, lo que supone que la creación lleva consigo la duración limitada y, al mismo tiempo, de la imposibilidad de una duración ilimitada se deduce la creación, que es el caso de San Buenaventura o, por el contrario, la no imposibilidad física de una duración ilimitada de un ser contingente, porque un infinito sucesivo, en el que lo pasado no permanece, no es un infinito físico en acto que es imposible, sino infinito físico en potencia, que no es imposible.

Esta cuestión, surgidà dentro de las escuelas filosóficas de la esfera del cristianismo se mueve en los límites entre la razón y la fe, ya que el filósofo cristiano, aunque como filosófo teóricamente, no tiene por qué partir de la verdad revelada que es de fe, lo cual corresponde al teólogo, sin embargo, no puede prescindir del dato contenido en la revelación, en la que se dice, desde el primer capítulo del primer libro, en el Génesis y es verdad repetida constantemente a lo largo del Antiguo y Nuevo Testamento, que el mundo ha sido creado por Dios, «en el principio», por tanto, con una duración temporal limitada. Unos, como San Buenaventura, consideran que esa verdad de fe es demostrable en su totalidad por la razón, tanto que el mundo ha sido creado, como que su duración es finita. Otros, como Santo Tomás de Aquino, consideran que la razón demuestra que el mundo ha sido creado, por ser contingente, pero la duración temporal del mundo es una noción aporética y, por tanto, indemostrable, es decir, que 
no se puede probar por la razón que la duración temporal del mundo tenga que ser necesariamente finita.

Encontramos que San Agustín plantea la cuestión de la creación del mundo con duración temporal limitada, principalmente a nivel teológico, en el ámbito de la fe y, sobre todo, en defensa de las Escrituras contra los maniqueos, acerca de la no incompatibilidad con la razón del hecho de la creación, ya que una creación temporal no es contraria a la noción misma de Dios como pretendían aquéllos. Mientras San Agustín había pertenecido a la secta de los maniqueos, había profesado su materialismo radical, que era de tal naturaleza que alcanzaba hasta el mismo Dios. Según la doctrina de Manes, Dios es luz, es decir, una substancia corporal divina brillante y muy tenue. Además, todas las cosas son de la misma substancia divina, por lo que el maniqueísmo identifica las criaturas a Dios, profesando un panteísmo radical en el que la materia no se diviniza sino, por el contrario, Dios es materializado. Recuerda San Agustín en «Las Confesiones», que cuando pertenecía a la secta de los maniqueos, «juzgaba que Tú, Señor, Dios de Verdad, eras un cuerpo luminoso e infinito y yo un pedazo de ese cuerpo». ${ }^{1}$

Dada la influencia y alcance de la doctrina maniquea en el ambiente cultural de la época, San Agustín, para contrarrestar las consecuencias individuales y sociales de tamaño error, enseñó con insistencia la «creación ex nihilo», frente a la concepción maniquea, en la que no hay creación propiamente dicha, pues el mundo viene a ser una porción de la substancia divina. Por otra parte, San Agustín insistió también en la duración temporal del mundo o creación «con el tiempo», para contrarrestar las críticas de los maniqueos que consideraban esto incompatible con la inmutabilidad divina y el error de los que afirmaban la coeternidad del mundo con Dios, como era el caso del neoplatonismo. Este, además de ser panteísta, afirmaba la necesaria producción del mundo a partir de la substancia divina, coincidiendo en el fondo con la noción maniquea de creación como separación de una parte de la unidad divina, al menos, en cuanto que la naturaleza de lo creado es divina, en los neoplatónicos, la creación es por emanación degragante, sin separación de lo Uno, como los rayos del sol que se hacen más tenues cuanto más se alejan del mismo sol, sin dejar de ser del sol, en los maniqueos, por separación de una porción de la substancia divina. A los ojos de S. Agustín, el mundo sólo puede tener dos orígenes, según se trate de la concepción neoplatónica o maniquea, por una parte, o la cristiana, por otra: o Dios produce el mundo a partir de su propia substancia, o lo crea de la nada. El primer caso lleva aparejada la necesaria eternidad de su existencia; en cambio, en el segundo, en cuanto tal, la existencia eterna no es necesaria y por tanto no viene exigida. Esta segunda concepción la recibe S. Agustín de la revelación divina en la Sagrada Escritura, y la defiende de los ataques e interpretaciones de los maniqueos.

San Agustín plantea la cuestión de la creación desde la misma fe, apologéticamente, en polémica contra todas las concepciones que niegan de hecho la realidad de la creación. En las argumentaciones de la «Ciudad de Dios» se percibe fácilmente que parte de la autoridad de la

1 San Agustín, «Confesiones» L.IV, c.16 nº 31. 
Escritura, ya que, antes de proceder al estudio de la creación, comienza con la afirmación: «Que Dios ha hecho el mundo a nadie creemos con más seguridad que al mismo Dios». ${ }^{2}$ Lo cual pone de manifiesto, con claridad, el carácter teológico, fundado en la fe, con el que aborda la especulación sobre la creación en la citada obra. Dice, además: «¿Dónde lo hemos oído? Acá nosotros nunca mejor que en las Escrituras Santas, donde dijo su profeta: En el principio hizo Dios el cielo y la tierra». ${ }^{3}$

Con relación a la cuestión de lạ duración limitada del mundo, San Agustín se encontró con una problemática filosófico-teológica muy distinta de la que afrontaría después Santo Tomás de Aquino. Para éste, vincular la temporalidad a la noción de creación representaba desechar como inaceptables los presupuestos filosóficos de Aristóteles, como lo habían hecho los franciscanos que se consideraban fieles seguidores de San Agustín en polémica con los denominados «aristotélicos» de la escuela del averroísmo latino, quienes, siguiendo la versión averroísta de Aristóteles con fuerte influencia neoplatónica, afirmaban la duración ilimitada del mundo que consideraban emanado de la substancia divina, no creado. El primero se veía en la necesidad de defender la no irracionalidad de las escrituras frente al maniqueísmo, por una parte y, por otra, la incompatibilidad de la emanación necesaria del mundo a partir de la substancia divina de los neoplatónicos con la fe cristiana. Aquél se encuentra con unos aristotélicos que deforman los presupuestos filosóficos del estagirita que los hace incompatibles con la fe cristiana, el valor de un auténtico aristotelismo, como verdad filosófica y compatible con la fe cristiana y los que polemizando con los falsos aristótelicos tienen el peligro de abandonar la vía verdadera para la especulación filosófica. Por otra parte, a esto hay que añadir que se solía comprender mal el Timeo de Platón como si éste hubiera afirmado la creación temporal del mundo, al hablar de un comienzo en su formación, contra lo que Aristóteles habría defendido la no creación, al enseñar la eternidad del mundo. En realidad, la doctrina del Timeo de Platón está bien lejos de la doctrina cristiana sobre la creación del mundo, ya que presupone la preexistencia de la materia caótica eterna y la acción divina sobre ella es informadora y ordenadora, pero no creadora. ${ }^{4}$

A pesar de las diferencias de planteamiento entre Santo Tomás de Aquino y San Agustín ante la cuestión de la creación temporal del mundo, sin embargo hay una analogía entre sus actitudes en defensa de la verdad. Santo Tomás aborda la cuestión de la creación del mundo en el tiempo y su formulación adecuada en el orden filosófico en defensa del valor de la Escritura, pues dar por demostradas cuestiones que no son demostrables, pone en peligro el resto de las verdades reveladas ante los ojos de los incrédulos, que podrían considerar que las restantes verdades reveladas estarían, al igual que ésta, aceptadas sin fundamento. Por eso, mientras enseña que la «creatio ex nihilo» en cuanto tal es una verdad que está al alcance de la razón humana, por otra parte, enseña que el comienzo temporal del mundo no es una verdad de razón, sino de fe.

2 San Agustín, «La Ciudad de Dios». L.XI, c. 4 no⒈

3 San Agustín, «La Ciudad de Dios». L.XI, c. 4 nº1.

4 Platón, «Timeo» $30 \mathrm{~b}$. 
«Por consiguiente, que el mundo ha comenzado a existir, es creíble; pero no es demostrable ni escible. Y esto conviene tenerlo muy en cuenta, no sea que, presumiendo algunos demostrar las cosas que son de fe, alegue razones no convincentes, con lo cual dé a los no creyentes ocasión de irrisión, juzgando ellos que por tales razones asentimos nosotros a las cosas que son de fe».5

Por este motivo, Santo Tomás polemiza contra los «murmurantes» en su opúsculo «De aeternitate mundi», porque afirmaban como verdad al alcance de la razón, el comienzo temporal del mundo, diciéndoles que, en sí misma, es verdad de fe y, por tanto, no demostrable por la razón. Por otra parte, los «murmurantes» hacen esto por oposición a la afirmación aristotélica de la eternidad del mundo, según la formularon e interpretaron los averroístas de la escuela del averroísmo latino que, para no ser tachados de herejes, inventaron la teoría de la doble verdad, según la cual, la creación del mundo no se podía demostrar por la razón, pero sí se podía afirmar basándose en la fe. Ahora bien, ambos errores, la demostrabilidad racional del principio temporal del mundo, al vincularlo al hecho de la creación y la consideración de que la creación es una verdad que pertenece exclusivamente a la fe, no accesible a la razón humana, aunque de distinta manera, ambas ponen en peligro la verosimilitud de la Escritura.

San Agustín, por su parte, encontró ante sí el neoplatonismo paganizante y el maniqueísmo que negaban de diferentes formas la creación «ex nihilo», pero coincidiendo en ser, ambas posiciones, panteístas. En el neoplatonismo, el mundo es una emanación de la substancia divina; y en el maniqueísmo, el mundo es una parte de la substancia divina. El panteísmo, subyacente en ambas concepciones, conduce necesariamente, por negación de la acción creadora trascendente, a afirmar la necesaria eternidad del mundo. Contra esas posiciones San Agustín lleva a cabo una defensa de la verdad revelada, según la cual el mundo ha sido creado «ex nihilo» con duración temporal limitada. Tal y como viene en la Escritura: «En el principio creó Dios el cielo y la tierra».

Contra los maniqueos, San Agustín defiende que la creación temporal no es absurda o contraria a la razón como pretendían ellos. Santo Tomás, por su parte, defiende que la afirmación de una duración ilimitada del mundo no es necesariamente contraria a la noción de creación «ex nihilo» y que considerar como demostrables y demostradas verdades reveladas que no son demostrables por la razón, va en detrimento de la misma verdad revelada y del valor de la Escritura. La actitud fuertemente polémica que sostiene San Agustín frente a los maniqueos ha podido ocultar a sus seguidores que San Agustín no era deudor de las nociones que ellos atribuían a la Escritura, es decir, que la noción de creación lleve en sí misma la razón de novedad en el ser.

En la obra «Del Génesis contra los maniqueos» San Agustín muestra, de la misma manera que en la Ciudad de Dios, que la cuestión de la creación que disputa con los maniqueos es considerada a nivel teológico de acuerdo con la interpretación de la Escritura como norma de fe. San Agustín se ve en la necesidad de defender a los fieles cristianos de las dificultades

5 Santo Tomás, «Summa Theologica». I, q. 46, a. 2. c. 
burlescas que proponían los maniqueos acerca de los textos de la Escritura y que aquéllos no sabían responder. Hay, pues, en San Agustín, dos motivaciones fundamentales: por una parte, defender una adecuada interpretación de la Escritura y, por otra, responder a las dificultades que burlonamente y con ánimo de desprestigio ponían los maniqueos. Se mueve, pues, en el ámbito de las verdades de fe y sus negaciones, herejías, pero no en el de los errores filosóficos en cuanto tales, aunque sí indirectamente.

«Acostumbran los maniqueos a vituperar las Escrituras del Antiguo Testamento, las cuales ignoran; y con este reproche, a los católicos débiles y niños en la fe, que no encuentran cómo responder a sus argucias, los engañan y se burlan de ellos».6

Los maniqueos, con el objeto de cuestionar la Sagrada Escritura en su totalidad, proponían dificultades de carácter filosófico a las afirmaciones de la revelación y así, contra el texto: «En el principio hizo Dios el cielo y la tierra», en el que todo el mundo entiende que el mundo fue creado por Dios, de la nada y con el tiempo, es decir, con duración temporal finita; ellos, con ánimo de ridiculizar las Escrituras, plantean la siguiente dificultad:

«Preguntan en qué principio y si en el principio del tiempo hizo Dios el cielo y la tierra ¿qué hacía Dios antes de crear el cielo y la tierra?».?

La pregunta puede ser considerada «en recto» como teológica, ya que se formula directamente sobre un texto de la Escritura y, además, escrutando directa y principalmente sobre el mismo Dios, presuponiendo la necesidad natural de toda actividad divina y en particular de la creación, a modo de «natura naturans» concebida como acción necesaria de su esencia. Pero, a su vez, también se puede examinar esta misma cuestión en su vertiente filosófica, en cuanto que se analiza la relación entre Dios y el mundo desde el punto de vista entitativo, apareciendo también, en el horizonte de la cuestión, la dimensión «temporal» que se presupone en el adverbio «antes» y que exige examinar la cuestión sobre si el tiempo es siempre, o si hay tiempo «antes» del tiempo.

Los maniqueos consideraban la imposibilidad de que Dios obrase, después de no haber obrado, porque suponían que toda acción exige una causa y en este caso esa causa debía ser algo distinto de Dios que desde fuera le hubiera movido impulsándole a obrar y como nada hay fuera de Dios, concluían que es imposible que «En el principio hizo Dios el cielo y la tierra». Y si esa afirmación no es verdadera, la Escritura es falsa y preguntan irónicamente: «¿Qué fue lo que repentinamente le agradó para hacer lo que nunca había hecho en tiempos eternos?».8

La dificultad presentada por los maniqueos hay que examinarla en una doble vertiente: por una parte, hay que considerar que la acción «ad extra»: de Dios no supone ninguna mutación

6 San Agustín, «Del Génesis contra maniqueos». L. I, c.1, n²2.

7 San Agustín, «Del Génesis contra maniqueos». L. I, c.2, nº3.

8 San Agustín, «Del Génesis contra maniqueos». L. I, c.2, nº3. 
en El, aunque esa acción haya sido realizada en un momento determinado y antes no se realizaba, porque Dios no es causa del mundo por naturaleza, sino por decisión libre y en El se identifica su entender con su ser, crea por el Verbo por ello, la creación ex nihilo con el tiempo no afecta a la inmutabilidad de Dios. La no resolución de esta cuestión conduce a afirmar la necesidad de la eternidad del mundo aun supuesto Dios y por tanto la falsedad del texto escriturario. Por otra parte, la noción de tiempo subyacente en la pregunta formulada por los maniqueos que se manifiesta con el témino «tiempos eternos», los precedentes la existencia del mundo el «antes» de la creación se identifica con la noción de eternidad. La eternidad, concebida como un tiempo infinito, es incompatible con la naturaleza divina. Tiempo, como medida del movimiento, sólo hay después de la creación y como medida del ser creado, no antes y medida del ser divino.

Para ver el significado de la exégesis que hace San Agustín del primer versículo del Génesis: «En el principio hizo Dios el cielo y la tierra», es conveniente mostrar los criterios de exégesis empleados por San Agustín al examinar la Escritura.

En la obra «Del Génesis a la letra incompleto», antes de comenzar la interpretación del primer versículo del Génesis, señala los diferentes niveles interpretativos que encuentra el exégeta en los textos de la Escritura de cara a su interpretación:

«De cuatro modos distintos exponen algunos tratadistas la ley; sus nombres pueden enunciarse en griego y explicarse en latín, según la historia, la alegoría, la analogía y la etiología».

Y explica, a continuación, cada uno de esos modos de entender la esneñanza de los libros sagrados:

«según la historia, cuando se narran los hechos ejecutados sean divinos o humanos. Conforme a la alegoría, cuando los hechos y dichos se toman figuradamente. Se exponen en sentido analógico cuando se demuestra la conformidad entre los pasajes del Antiguo y del Nuevo Testamento. Y según la etiología, cuando se dan las causas o se dice por qué los hechos y dichos». ${ }^{10}$

Por su parte, Santo Tomás de Aquino, al comienzo de la Suma Teológica I, q.1, a.10, explica los sentidos de la Sagrada Escritura y señala que, en los libros sagrados, además de los que significan las palabras, a su vez, las cosas significadas por las palabras significan algo distinto. Lo que signfican las palabras mismas pertenece al sentido histórico o literal, y lo que significan las cosas expresadas se llama sentido espiritual que se apoya en el literal y lo supone. El sentido espiritual, según Santo Tomás, admite tres significados distintos: en cuanto que la Antigua ley es figura de lo que contiene la Nueva, es el sentido alegórico; en cuanto que lo

9 San Agustín, «Del Génesis a la letra incompleto». C. II, nº 5.

10 San Agustín, «Del Génesis a la letra incompleto». C. Il, nº 5. 
cumplido en Cristo es lo que debemos hacer, es el sentido moral, y, en cuanto significa lo que hay en la gloria es el sentido anagógico. El mismo pone de manifiesto la coincidencia de ambas concepciones:

«De las cuatro sentidos agustinianos, tres, historia, etiología y analogía, pertenecen al sentido literal... El otro sentido agustiniano, esto es, el alegórico, equivale a los tres sentidos espirituales.....11

Por eso, de acuerdo con sus propios criterios, San Agustín, al comenzar la exégesis de texto: «En el principio hizo Dios el cielo y la tierra», dice: «Luego sobre esto que se escribió: En el principio hizo Dios el cielo y la tierra» puede preguntarse si debe ser entendido solamente según el sentido histórico, o también, si significa alguna cosa figuradamente» ${ }^{12} \mathrm{y}$, de forma análoga, en la obra «Del Génesis a la letra», dice: «En la narración de las cosas hechas nos preguntamos si todas se han de tomar únicamente en sentido figurado o han de aceptarse y defenderse, también, conforme al histórico y literal». ${ }^{13}$ Con esto, nos pone de manifiesto, su intención de acercarse a los textos con sentido religioso y e forma que la labor del exégeta debe estar supeditada, en su mente, a las verdades de la fe, de maneraq que la Sagrada Escritura no puede, ni debe ser manipulada a gusto de quien la interprete como si su estudio estuviera totalmente indefinido. No se puede utilizar la Escritura para acomodar su enseñanza a la opinión de cada uno, como hacen los herejes, sino al revés:

«como los herejes acostumbran a exponer las diversas Escrituras acomodándolas a sus opiniones, las cuales están en contra de la fe, de la doctrina católica, antes de presentarla en este libro, se ha de proponer brevemente la fe católica.» ${ }^{14}$

San Agustín, por lo tanto, nos muestra la intención de acercarse a los textos de la Escritura para examinarlos a la luz de la fe. Después efectúa sobre ellos una defensa racional para mostrar a los maniqueos que lo contenido en la verdad revelada no es contrario a la razón, como ellos pretendían. La tarea de San Agustín es formalmente teológica, su examen se funda en la autoridad divina, pero a la hora de polemizar con los maniqueos, con espíritu àpologético, su argumentación se mueve en el ámbito de la razón humana.

La célebre cuestión fillosófica que aparece implícita en la apología que hace San Agustín del primer versículo del Génesis en contra de los maniqueos, relativa a si el mundo podía haber sido eterno, siendo creado, nos pone de manifiesto la existencia de límites en el alcance del conocimiento de la razón humana.

Teniendo en cuenta la respuesta dada a esta cuestión por Santo Tomás de Aquino, se puede decir que la contingencia del mundo, cognoscible por la razón humana, pone de manifiesto que

11 Santo Tomás de Aquino, «Summa Theologica». I, q.1, a.10 ad 1um.

12 San Agustín, «Del Génesis a la letra incompleto». c. III, $\mathrm{n}^{\circ} 6$.

13 San Agustín, «Del Génesis a la letra». c.1, 1.

14 San Agustín, «Del Génesis a la letra incompleto». C. I, $\mathrm{n}^{0} 1$. 
no posee el ser por sí mismo y que por lo tanto, lo tiene recibido, es decir, que ha sido creado. Ahora bien, puesto que Dios es infinito y no es imposible en sí mismo un mundo de duración ilimitada, puesto que no es contradictorio, no sería imposible que Dios hubiera creado el mundo, si hubiera querido, «ab aeterno». No obstante, según Santo Tomás, el hombre sólo puede conocer por revelación divina que el mundo ha sido creado con el tiempo, es decir, con principio temporal, según la enseñanza de la Escritura en el primer versículo del Génesis: «En el principio hizo Dios el cielo y la tierra». 